\title{
RECREACIONES TEATRALES DE LA PASIÓN. TERCERA DIFERENCIA SOBRE LA MUERTE DE JOSÉ MANUEL CORREDOIRA
}

\author{
FranCisco GUtiérRez CARbajo \\ UNED \\ fgutierrez@flog.uned.es
}

\section{RESUMEN}

Las recreaciones dramáticas de la vida de Cristo surgen desde los orígenes del teatro español. Las versiones de la Pasión presentan con frecuencia una finalidad didáctica, pero no escasean las representaciones que acentúan los elementos paródicos, las que siguen los arquetipos del mito o las que son claramente desmitificadoras. Buena parte de ellas han sido realizadas por autores ajenos a ideologías y creencias religiosas. Después de una revisión sintética de la principales recreaciones de este asunto, se analiza la que lleva a cabo en la Tercera diferencia sobre la muerte José Manuel Corredoira, uno de los dramaturgos más representativos y transgresores del teatro español actual.

Palabras Clave: Recreación. Versión. Adaptación. Teatro. Corredoira.

\section{Abstract}

Dramatic recreations of the life of Christ have appeared since the beginnings of Spanish theatre. Versions of the Passion frequently show a didactic purpose, but performances that emphasize parodic elements, those that follow the archetypes of the myth, or those that clearly demythologize the subject, are not uncommon. Many of them are carried out by playwrights with no ideological or religious bias. After a syntactic revision of the most significant recreations of this topic, we analyze the one attempted 
in the Tercera diferencia sobre la muerte (A Third Difference on Death) by José Manuel Corredoira, one the most representative and transgressive playwrights of Spanish drama nowadays.

KEY WORDS: Recreation, version, adaptation, drama, Corredoira.

Las recreaciones teatrales de la pasión de Cristo datan de los mismos orígenes del teatro español y han alcanzado un nuevo florecimiento en los últimos años. Con frecuencia han presentado una finalidad didáctica pero no escasean las versiones que acentúan los elementos paródicos, las que siguen los arquetipos del mito o las que son claramente desmitificadoras. Entre todas estas recreaciones, la que lleva a cabo José Manuel Corredora Viñuela (Gijón, 1970) en la Tercera Diferencia sobre la muerte (2014) es una de las más brillantes y sorprendentes.

La obra teatral de Corredoira está profundamente enraizada en el mundo clásico a la vez que aparece vinculada con las corrientes más experimentales y vanguardistas. En este sentido, su dramaturgia ha sido saludada como una de las más originales e innovadoras en lengua española del panorama teatral actual y ha merecido estudios y valoraciones muy positivas de Fernando Arrabal (2008), Juan Goytisolo (2010), Domingo Miras (2012), Jerónimo López Mozo (2012), Ricardo Senabre (2014) y de otros dramaturgos e investigadores ${ }^{1}$.

Este lector atento de Aristófanes, Luciano, Rabelais, Lucas Fernández, Cervantes, Quevedo, Calderón, Sterne, Jarry, Valle-Inclán, Joyce, Céline..., que es José Manuel Corredoira, también lo es del Julián Ríos de Larva, según Juan Goytisolo, y de otros muchos autores, de los que incorpora las mejores de sus técnicas: «Alterna los breves intercambios plurilingües de personajes estrafalarios con monólogos cuya erudición exhaustiva, de una inigualable comicidad, sorprende y cautiva a quien se adentra en ellos y sueña en su representación escénica. La apuesta es alta y sobre todo insólita en estos tiempos de mediocridad comercial y desprecio a la inteligencia del lector y espectador.» (Goytisolo, 2010: 7). Atendiendo a esta fuerza torrencial del verbo, a su potencia expresiva, los críticos lo han comparado también con el autor de Luces de bohemia: «Se tiene la impresión de que, como el Valle-Inclán de la madurez, Corredoira se esfuerza por encontrar un lenguaje total...» (Senabre, 2014:16).

Sobre este poderío verbal insiste Jerónimo López Mozo, al analizar el teatro de Corredoira: «Todo un desafío a la inteligencia del lector y del director de escena. La palabra se erige en la gran protagonista. El vocabulario es rico y alumbra un lenguaje que, como sucedía con el de Valle, es un desafío al diccionario de la lengua. Rescata de sus recovecos voces en desuso o se las inventa». (López Mozo, 2012: 15-16). El mismo López Mozo ha contextualizado muy certeramente la dramaturgia de José Manuel Corredoira:

\footnotetext{
1 Por mi parte, he analizado la presencia del animal no humano en Bestiario de amor y el componente erótico de su teatro en Retablo de ninfas (Gutiérrez Carbajo, 2011:168 y 2012: 76-77), la singularidad de su discurso en el Diario de Ezequiel Wilkins y su torrente expresivo en el prólogo a Elucidario sentimental (Gutiérrez Carbajo, 2013a: 501-502 y 2013b: 7-23). Sobre el zoomorfismo en el teatro puede consultarse Francisco Gutiérrez Carbajo, «El animal no humano en algunas obras teatrales actuales», en Anales de la Literatura Española Contemporánea, 34. 2 (2009), 67 / 453 - 90/ 476.
} 
En los últimos cincuenta años es frecuente, en el teatro español, la aparición de dramaturgos que rompen, no solo con el que en cada momento triunfa en los escenarios comerciales, sino también con el que proponen sus colegas más vanguardistas o innovadores. De ese grupo forman parte Arrabal, Nieva, Romero Esteo y Riaza. A él ha venido a sumarse, en los albores del nuevo siglo, José Manuel Corredoira (Gijón, 1970), autor de una decena de obras (López Mozo, 2012: 15).

Otro de los más representativos dramaturgos actuales, Fernando Arrabal, observa que Corredoira concibe su creación como un extravío de lucidez, y subraya la organicidad tan difícil de lograr en una obra tan imprevisible y tan atinadamente deconstructora: «Forma y fondo, espíritu y delirio, semejantes en todo punto, se unen para ser uno solo. Ajusta sus impulsos a la sombra de su furor, a fin de caminar a lo largo del sendero de los tiempos venideros. Las cosas fugaces devienen eternas, y las bestias tan conmovedoras como los siglos que pasan» (Arrabal. 2008: 8).

Domingo Miras en el prólogo a Iluminaciones al público subraya la desbordante imaginación y audacia de esta obra y señala algunas características que son perfectamente aplicables a todo el teatro de Corredoira:

Una forma desbordante de imaginación y de audacia. Es el desenfreno verbal que se derrocha a manos llenas, que se descarga abrumadoramente sobre el incauto lector que esperaba una obra al uso y se encuentra ante un extraño monstruo, un dragón retorcido y pintoresco hasta lo indecible en que las palabras más inesperadas, los neologismos más estrambóticos, que caen como un diluvio torrencial, son como las brillantes escamas de colorines con que difumina su perfil en un juego permanente de sorpresas encadenadas. Extravagancias, que decía Goethe, o locuras, como dirá algún probo funcionario, el más brillante teatro de vanguardia está servido» (Miras 14).

La dramaturgia de Corredoira establece múltiples puentes con todas las manifestaciones artísticas y con las diversas disciplinas científicas y filosóficas y construye sus personajes atendiendo a lo emocional y cognitivo, a lo sensitivo y racional:

En consonancia con lo que constituyen las teorías científicas más actuales, presenta a los personajes formados por esa dialéctica de fuerzas, por el reflexionar y por el sentir, por el pensamiento y la emoción, por la meditación y la pasión.

En el teatro de Corredoira, como en la fenomenología de Edmund Husserl, se logra la simbiosis de términos opuestos, y la afirmación de la identidad entre ser y parecer no suprime, sino que por el contrario fundamenta adecuadamente la distancia entre «ser verdaderamente» y el «parecer, pero no ser» (Gutiérrez Carbajo, 2013: 22-23).

En la recreación de la pasión de Cristo que Corredoira lleva a cabo en la Tercera Diferencia sobre la muerte (2014), el autor pone de manifiesto una vez más una cultura enciclopédica, un imponderable conocimiento de las diversas materias humanísticas y científicas y un dominio del lenguaje que constituyen para el lector-espectador una inestimable fuente de conocimiento y una impagable y complaciente fruición.

Puede resultar sorprendente que la pasión de Cristo constituya el asunto básico de una obra teatral de José Manuel Corredoira, que está considerado uno de los dramaturgos más transgresores del momento actual. Sin embargo, algunas de las obras que directa o indirectamente han influido en esta recreación pertenecen a autores nada preocupados por los asuntos religiosos o que se declaran abiertamente ateos. Pero no es infrecuente 
que el mejor observador sea el que se encuentra fuera del asunto que analiza y disecciona, ya que, desde esta perspectiva, sus guías fundamentales suelen ser la imparcialidad y la objetividad, dos requisitos indispensables en cualquier ciencia y muy especialmente en la filológica.

Además, abordando este asunto, Corredoira se instala en un escenario construido por los más destacados dramaturgos que le otorgan a la muerte un papel semejante al que Max Scheler le asigna en las culturas antiguas: se convierte en un poder rector y conformador de la vida, algo que le confiere a esta articulación y sentido. Incorporando la muerte a sus repertorios, estos dramaturgos se instalan en una tradición que recorre toda la historia de la literatura y del teatro. Desde el despertar de las culturas egipcias, pasando por la tragedia clásica, por el «sarcasmo conceptual» de las danzas macabras medievales y por la poesía elegíaca de muchas canciones y decires hasta llegar a la lírica y al teatro románticos y a la elegía funeral de la poesía moderna, todas las manifestaciones artísticas, y muy especialmente el teatro, han representado las más diversas manifestaciones del pensamiento de la muerte. Los trabajos de Siciliano (1934) sobre Villon y de Pedro Salinas (1947) sobre Jorge Manrique constituyen muestras muy significativas de la cultura de la muerte en la Edad Media. Aparte de su presencia en la mayoría de las obras de carácter moral — la que Salinas denomina «literatura difusa de la muerte» cristaliza este asunto en una serie de formas definidas como dicterios, plantos y disputas-, ha seguido su curso a la largo de la historia y ha vuelto a cobrar un papel de auténtico protagonista en nuestros días.

En este contexto puede entenderse de una manera más cabal la recreación de la pasión que lleva a cabo José Manuel Corredoira, que se incorpora, así, a una interesante tanatología teatral, en la que destacan, entre otros, Artaud, Jean Genet, Kantor, Heiner Müller y Jan Fabre.

Antonin Artaud en El teatro y su doble afirma que «El teatro, como la peste, es una crisis que se resuelve en la muerte o la curación» (Artaud, 1990: 34), y en una línea semejante, «Genet, que fue de especial importancia para Heiner Müller, coincide con este autor posdramático en la idea de que el teatro sería un diálogo con los muertos» (Lehmann, 2013: 122).

Kantor es el creador moderno del Teatro de la muerte: «La forma ceremonial que ocupa el lugar del drama es, en el caso de Kantor la danza de la muerte. El propio autor destaca: «El misterio de la muerte, una dance macabre medieval, tiene lugar en un aula de escuela» (Lehmann, 2013: 125). Se refiere a su obra La clase muerta. Kantor desarrolla este asunto en otros trabajos: «El miedo existe. El miedo frente al mundo exterior, el miedo al destino, el miedo a la muerte, el miedo a lo desconocido, a la nada, al vacío» (Kantor, 2010: 139).

Por su parte, el dramaturgo belga Jan Fabre, que ha revolucionado las artes escénicas contemporáneas, no ha dudado en afirmar que «el teatro es una preparación para la muerte» (Fabre, 2009: 15), y que «la verdad sólo se encuentra en situaciones extremas» (Font, 2008).

Corredoira, siguiendo en este caso a Bataille, comenta que la muerte es un «obstáculo cómico», y en efecto, para Bataille todo el mundo es una parodia, la experiencia tiene un carácter inaprensible y el objeto del conocimiento epistemológico solo es alcanzable mediante el placer, que siempre es dinámico frente al dolor estático de la muerte. Algu- 
nos de sus libros, como la Suma ateológica, concitaron la crítica de los existencialistas como Sartre, para quien Bataille sobrevive a la muerte de Dios. En la órbita del existencialismo cristiano, el dramaturgo y filósofo Gabriel Marcel considera que Bataille no tiene la sinceridad que hacía de Nietzsche un místico. Georges Bataille, sin embargo, estuvo muy marcado por la lectura de Nietzsche, como lo estuvo por la de Pascal, dos autores de gran influencia también en Corredoira.

El reto al que se enfrenta Corredoira no viene determinado solo por el tema que aborda sino también por la excelencia de los autores que lo han estudiado. No intentaré presentar la inmensa bibliografía sobre esta cuestión - tarea casi imposible, aunque me limitase a una selección ${ }^{2}$ - pero no quiero dejar de citar algunos de los hitos fundamentales.

En primer lugar, el profesor Miguel Ángel Pérez Priego argumenta con su tino habitual que el Auto de la Pasión de Alonso del Campo, documentado modernamente en el trabajo de las archiveras Carmen Torroja Menéndez y María Rivas Palá (1977), «tal como hoy lo conocemos, es una fragmentaria recreación dramática, en unos seiscientos versos, de algunos episodios de la Pasión de Cristo: la oración en el huerto, la traición de Judas y el prendimiento del Maestro, las negaciones de Pedro, la sentencia de Pilatos, y el encuentro de San Juan y la Virgen» (Pérez Priego: 2009:67). Se aborda también este asunto, que inspira la pieza de Corredoira, en las Lamentaciones fechas para la Semana Santa de Gómez Manrique, que «son propiamente una versión en lengua vulgar del Planctus Mariae» (Pérez Priego: 2009: 74).

Juan del Encina, considerado con toda propiedad por Pérez Priego como el padre del teatro castellano, representa dramáticamente los últimos días de Cristo, siguiendo la disposición formal del drama litúrgico:

En la Representación a la Pasión, sobre la estructura del drama litúrgico, introduce los nuevos personajes del Padre y del Hijo y, sobre todo, la figura de la Verónica, que da pie a la narración patética de la Pasión por un testigo directo y que permite la incorporación de un sugestivo elemento escenográfico con la exhibición del velo en el que se imprimió la faz de Cristo, que tratará de mover a piedad al espectador. El monumento sepulcral y el canto del Vexilla regis proceden del ceremonial litúrgico de algunas iglesias para el viernes santo (Pérez Priego, ed., 1996: XXIX).

El Auto de la Pasión de Lucas Fernández, de notable influencia en la Tercera Diferencia sobre la Muerte de Corredoira, lo considera Pérez Priego la obra religiosa más importante de ese autor, y lo explica como una «patética rememoración escénica de la pasión de Cristo por medio de sendos y sucesivos monólogos de Pedro y Mateo, que narran emotivamente aquellos sucesos» (Pérez Priego, 2003:31). Por lo que se refiere a la escenografía, «todo indica que se requeriría un escenario múltiple y simultáneo, con distintas mansiones que ocuparía cada uno de los personajes que van interviniendo en la acción» (Pérez Priego, 2003: 32).

\footnotetext{
2 Una muestra de ello es la tesis doctoral de Isabel Mira Ortiz, Semana Santa y textos literarios de la pasión en la región de Murcia, defendida el 29 de junio de 2006 bajo la dirección de Javier Díez de Revenga y publicada en Murcia, Universidad de Murcia, 2009.
} 
El anónimo Aucto del Descendimiento de la $\mathrm{cruz}^{3}$ arranca de una costumbre muy habitual desde el siglo XIV en todo el Reino de Castilla y en otros lugares, aunque se escenificaba en descampados a las afueras de las poblaciones. Este antiguo rito contemplaba normalmente la crucifixión, muerte y bajada de Cristo de la Cruz, para entregarlo a su Madre y ha sido estudiado, entre otros, por Fernando Lázaro Carreter, José M. Domínguez Moreno, Antonio Sánchez del Barrio, Francesc Massip y M ${ }^{a}$. de la Pau Jarner, etc. ${ }^{4}$ El descendimiento de la cruz ha merecido las obras de Peter Paul Rubens, Roger van der Weyden, Fra Angelico, Caravaggio, Pedro Machuca, Francisco de Goya...

En el teatro del Siglo de Oro se encuentran continuas referencias a la Pasión de Cristo. Por ejemplo, en Las órdenes militares de Calderón de la Barca hay varias alusiones a este asunto. Así, los músicos cantan: «El Mundo al Adán Segundo/ roja cruz en premio ha dado» (vv. 812-813). Por su parte, el Segundo Adán realiza la siguiente invitación: «...Cualquiera/ tome su cruz y me siga./Y que no lo digo advierta/ que tome la mía porque/ sé que para ella no hay fuerzas», vv.1838-1841 (Ruano de la Haza, ed. 2005: 35).

En La siembra del Señor, que se publicó por primera vez con el título de Los obreros del Señor y fue atribuida a Rojas Zorrilla en el volumen Autos sacramentales con cuatro comedias nuevas, y sus loas y entremeses (Madrid, María de Quiñones, 1655), — según Mariela Insúa y Carlos Mata, la autoría calderoniana resulta incuestionable-, se insiste en la pasión y muerte de Cristo. En este auto sacramental, construido en su estructura alegórica general sobre la parábola de los obreros de la viña (Mateo, 20, 1-16) y, en menor medida, sobre la de los viñadores infieles, pero también, en algunos detalles concretos, en la parábola del sembrador, la de la semilla y la cizaña y la de los talentos, una vez sembrado y nacido el trigo, la Culpa, con la ayuda del Sueño, intentará viciar el fruto a través de la acción de tres enemigos: la cizaña, la langosta y la neguilla (el Judaísmo, la Idolatría y la Apostasía). Al final, el Judaísmo dará muerte al hijo del mayoral, Emanuel, representación de la pasión y muerte de Cristo (Insúa-Mata, 2013).

El Teatro Corsario realizó una versión de la Pasión en 1988 a partir de textos de los evangelios, de Diego de San Pedro y del Libro de la oración y meditación de Fray Luis de Granada. Este espectáculo, que ha conocido numerosas representaciones, recrea las tallas y las esculturas que pueden verse en las procesiones, como declaraba el director del grupo Fernando Urdiales: «Las imágenes reposan en el silencio de las hornacinas. Al levantarse el telón reciben un soplo de vida que les permite vivir una vez más la historia para la que fueron esculpidas. Se ponen en movimiento para mostrar invariablemente el drama por medio de sus efectos casi humanos» ${ }^{5}$. Fernando Lázaro Carreter ha resaltado lo que tiene de peculiar esta representación, y que la fuerza con que se consigue reflejar

${ }^{3}$ La Biblioteca Virtual Miguel de Cervantes conserva una reproducción digital, de este auto a partir del microfilm del manuscrito original de Colección de Autos sacramentales, Loas y Farsas del siglo XVI (anteriores a Lope de Vega), ff. 430r-434v. Localización: Biblioteca Nacional (España). Sig. Ms. 14711.

${ }^{4}$ Fernando Lázaro Carreter, Teatro Medieval, Madrid, Castalia, 1970; José M. Domínguez Moreno: «La función del Descendimiento en la Diócesis de Coria (Cáceres)», en Revista de Folklore, nº 77 . Va1ladolid, C. Ah. Popular, 1987. pp. 147-153; Francesc Massip y Mª de la Pau Jarner, «Cataluña, Islas Baleares y País Valenciano», en El Auto Religioso en España, Madrid, Comunidad de Madrid, 1991; Antonio Sánchez del Barrio, «El rito del descendimiento en la villa de Olmedo (Valladolid)», Revista de Folklore, 127 (1991), pp. 23-26.

5 Cristina Fanjul, «San Isidoro, la catedral de Astorga y la Encina acogen la "Pasión" de Teatro Corsario», Diario de León, 19 de agosto de 2010. 
el Siglo de Oro es tal que parece que las tallas de los grandes imagineros salen de su albergue en San Gregorio para subir a las tablas:

«Pasión es, ya lo he dicho, una representación peculiar de los acontecimientos que rodearon la muerte de Cristo, tomando como motivo para su glosa y exégesis diversas imágenes y grupos escultóricos de la escuela castellana, muy en primer término los que acoge el gran museo vallisoletano. A lo largo de ocho cuadros, la compañía compone varios de aquellos célebres pasos, con extraordinaria fidelidad. Los personajes, estáticos en el momento inicial, descomponen en el gesto y, en su caso, el grupo, con movimientos que no dejan de ser noblemente plásticos para reproducir el instante evangélico(...)Nuestro teatro del cuatrocientos, claro es, cedió a la poderosa sugestión de aquellos trances dramáticos, pero hubo de dar un rodeo, para afrontarlos. Consistió en que los hechos fueran relatados por testigos. Encina introduce a dos ermitaños a quienes la Verónica cuenta los sucesos; Fernández, a cuatro santos y a tres Marías que también testifican. Son, en realidad, narraciones, pasiones trovadas, al modo de la de Diego de San Pedro, con solo diálogo (...) En la Pasión del Teatro Corsario se desanda el camino: desde las imágenes se va al encuentro de sus orígenes literarios, aunque solo en los fragmentos de Diego de San Pedro utilizados. No puede ser objetable el empleo directo del Evangelio, incluso en latín en algunos coloquios...» (Lázaro Carreter, 1990: 12).

En una línea semejante, la compañía «Nao D'amores», dirigida por Ana Zamora, en El misterio del Cristo de los Gascones ${ }^{6}$, se basa en la antigua representación que se hacía en la iglesia de San Justo de Segovia, en la que se bajaba del presbiterio una talla articulada de madera del «Cristo de los Gascones» en una función en la que se mezclaba el teatro y la liturgia.

En esta línea, Antonio Sánchez del Barrio (1987) y María José Martínez Martínez (2009) nos han proporcionado interesantes noticias sobre la «Pasión Tradicional» y los «crucificados dolorosos».

Una representación muy libre de la pasión de Cristo es la que lleva a cabo Fernando Arrabal en El cementerio de automóviles ${ }^{7}$, cuyos problemas con la censura han sido analizados por Berta Muñoz Cáliz (2005) ${ }^{8}$. El tema de la crucifixión también es tratado por Arrabal en Oración (1957), y el Cavanosa (Casanova) de El gran ceremonial (1963) es asimilado igualmente a Cristo como Ecce Homo (látigo con clavos, bata morada, cordón, caña, corona de espinas...). Según Fernando Cantalapiedra, lo que hace Arrabal en esa obra es «trasladar a los años sesenta la clásica iconología cristiana de la pasión de Cristo pinturas, tallas, autos sacramentales, procesiones...» (Cantalapiedra-Torres Monreal, 1996: 126).

${ }^{6}$ Fue estrenada en el año 2007 con la colaboración de Fundación Teatro de la Abadía y Juntas de Cofradías de la Semana Santa de Segovia.

${ }^{7}$ La obra, aunque escrita en 1957, no fue estrenada hasta el año 1977 en el Centro Dramático Nacional, bajo la dirección de Víctor García.

${ }^{8}$ Reproduzco solo uno de los informes recogidos: Alfredo Mampaso (17/12/68): «Emanu (Nuestro Señor Jesucristo) y sus dos compañeros, forman una especie de comparsa de payasos que tocan la trompeta para los pobres y eso irrita a los ricos que le envían a los guardias. Emanu cree saber lo que es bueno y verdadero y al hacer gala de ello demuestra su completa contradicción con la sociedad (el cementerio de automóviles), que vive, hace el amor y se comporta de acuerdo con sus reglas en las que no entran las teorías, ni el comportamiento de Emanu. Dentro del teatro del absurdo, el autor, hace una vil parodia de la Pasión de Nuestro Señor Jesucristo. Incurre en todas las Normas de Censura y por lo tanto procede su Prohibición»(Muñoz Cáliz, 2005) 
El asunto es abordado igualmente por el guionista y dramaturgo británico Edward Bond en Pasión (1971), una obra antibelicista, que cuestiona el papel de la monarquía (Bond, 1989).

El dramaturgo Alfonso Zurro en su pieza En el Monte del Olvido (2009) combina hábilmente elementos del teatro de Beckett y del drama bíblico. Al igual que en la versión de Corredoira la acción dramática se centra en los dos ladrones, que, según el propio autor, hablan de todo lo divino y lo humano 9 . Como observa Eduardo Pérez-Rasilla, esta obra asume todas las posibilidades de las numerosas representaciones de la Pasión de Cristo en el teatro, desde la «parodia» a la «nueva codificación del mito», pasando por la «rehumanización del personaje» o su «desmitificación». La comparación de la obra de Zurro con Esperando a Godot de Samuel Beckett no es desacertada, y en este sentido los críticos que defienden el carácter cristiano de la obra beckettiana, como Fraser, MacCoy, Kenneth, Rexroth, Leonard Pronko, etc., encuentran analogías entre Wladimir y Estragón con los dos ladrones crucificados a los lados de Cristo, y observan que el árbol que aparece en el segundo acto guarda un cierto simbolismo con la cruz.

En Gólgota picnic de Rodrigo García (Centro Dramático Nacional, 2011), el músico Mario Formenti interpretaba desnudo al piano Las siete últimas palabras de Cristo en la Cruz de Joseph Haydn. García lleva a cabo una crítica de la modernidad, del consumismo y de la desigualdad social, tomando como motivo los últimos momentos de la pasión de Cristo en la Cruz. La obra recibió muy duras críticas en Francia y en Polonia, y fue considerada blasfema por el clero. En Toulouse, donde goza de gran predicamento la dramaturgia de Rodrigo García, y es estudiada por prestigiosos investigadores de la Universidad de Toulouse-Le Mirail, el arzobispo de la ciudad, Robert Le Gall, declaró que la obra contaminaba la fe de muchos creyentes. En Polonia, los católicos y los activistas nacionalistas protestaron contra la puesta en escena de esta pieza en 2014, y, al igual que en Francia, recibió duras críticas de las altas jerarquías de la Iglesia Católica.

En España la gente se escandalizó sobre todo porque en cada función utilizaba unos 200 kilos de pan de hamburguesas, con los que forraba el suelo del teatro María Guerrero. Rodrigo García presenta a Cristo como un ser vanidoso, celoso, envidioso, loco, etc. Es un texto que tiene momentos interesantes atravesados por otras escenas menos afortunadas. El recurso esencial que utiliza Corredoira es subrayado por Rodrigo García, como fundamento de su obra: «Y la cruz y la muerte fueron embellecidas — cómo no— por el lenguaje, que es el principio de todo» (García, 2011: 47).

En cuanto a las representaciones populares de la Pasión se conservan testimonios de estos espectáculos en Pollença (1355), Villarreal (1369), Castellón (1383)..., y continúan en la actualidad en Nancy (Francia), Tegelen (Países Bajos), Budaörs (Hungría), St. Margarethen (Austria), Mariekerke (Bélgica), Erl (Austria), Oberammergau (Alemania), Iztapalapa (México), Paraguay, Perú y Filipinas (Brachetti, 2007); en Esparreguera, Olesa, Sant Vicenç dels Horts, Molins de Rei, Manresa, Martorell, La Palma de Cervelló Verges y otros muchos lugares de España. En Verges, por ejemplo, se representa con el telón de fondo de su museo municipal, desde el siglo XV.

\footnotetext{
${ }^{9}$ La obra se estrenó en el Teatro Central de «La Cartuja» de Sevilla el 3 de febrero de 2009 bajo la dirección de Manuel Llanes.
} 
En el contexto del teatro religioso de duelo se ha comparado la representación de la pasión de Cristo con la del martirio de Hussein, conocida como «Ta'ziya», que forma parte esencial de la tradición y de la doctrina chií en el Islam (Malekpour, 2004, Megid, 2009) $)^{10}$.

No faltan representaciones musicales de la Pasión. De Johann Sebastian Bach, por ejemplo, se conservan, La Pasión según san Juan y La Pasión según san Mateo, con texto y música; La Pasión según san Marcos, de la que se ha perdido la música; y una Pasión según San Lucas, obra de otro compositor, que fue copiada por Bach, a la que hizo algunos retoques. La pasión griega (título original en inglés, The Greek Passion; en checo Řecké pašije) es una ópera en cuatro actos con música y libreto de Bohuslav Martinu , basado en la obra La pasión griega o Cristo de nuevo crucificado del autor griego Nikos Kazantzakis. Se estrenó en la Ópera de Zúrich el 9 de junio de 1961.

La pasión y en general la vida de Cristo han sido objeto de versiones fílmicas por parte de directores como Pier Paolo Pasolini, Cecil B. DeMille, Martin Scorsese, George Stevens, Nicholas Ray y Mel Gibson. La más expresionista y tremendista es, sin duda, la de este último, que no ahorra torturas y suplicios, que nos recuerdan las pinturas tenebristas de Caravaggio.

Una versión paródica es la que nos presenta La vida de Brian (Life of Brian), el tercer largometraje del grupo de comedia inglés Monty Python. La película fue dirigida por Terry Jones, con guion de Terry Gilliam, Eric Idle, John Cleese, Michael Palin, Graham Chapman y del propio Terry Jones. Fue financiada por George Harrison, que escribiría después un tema para otra película de los Monty Python, El sentido de la vida.

Con los referentes mencionados, y con otros que irán indicándose en el análisis del texto, la obra de Corredoira se estructura fundamentalmente sobre la pasión y muerte de Jesucristo y de los dos ladrones que lo acompañaron en el calvario. Lo que en un primer momento determinó al autor a escribir sobre este asunto fue la contemplación en la Capilla Real de Granada de los cuadros flamencos sobre el descendimiento de la cruz de Hans Memling, Rogier van der Weyden, Pietro Perugino, Dierik Bouts..., que le impresionaron hondamente.

Conserva también el recuerdo del Auto de la Pasión de Lucas Fernández, especialmente de versos como los siguientes « ¡Oýd la passión rabiosa / que en su humanidad preciosa / sufre nuestro Dios jocundo», vv. 3-5 (Hermenegildo, 1972: 281), y «iO, qué fue verle acezando / con vna cruz muy pesada, / cayendo y estropeçando / y leuantando, / con la cara ensangrentada, // con la boz enrronquecida, / rompidas todas las venas / y la lengua enmudecida, / con la color denegrida, / cargado todo de penas, / y los miembros destorpados, / los ojos todos sangrientos, / los dientes atenazados, / lastimados / los labrios con los tormentos!», vv. 392-406 (Hermenegildo, 1972: 294).

Corredoira Viñuela ha consultado con detalle las obras de John Lihani, El Lenguaje de Lucas Fernández (1973) y de Alfredo Hermenegildo, Renacimiento, teatro y sociedad. Vida y obra de Lucas Fernández (1975), consideradas como dos importantes monografías sobre la obra de Lucas Fernández por el profesor Pérez Priego (2003: 32).

${ }^{10}$ Intidhar Ali Gaber Al-Harishawi, «La Pasión de Jesucristo y la Ta'ziya como formas del teatro religioso de duelo» Tonos digital. Revista de estudios filológicos, nº 26, enero 2014 (fecha de consulta, 21 de septiembre de 2014). 
Influye igualmente en la pieza de nuestro dramaturgo el Libro de la oración y meditación de Fray Luis de Granada, donde se describe la pasión y muerte de Cristo con un patetismo y una intensidad insuperables. Esta obra, según confiesa el propio Corredoira, ha sido uno de los descubrimientos más importantes de su vida lectora. Fray Luis de Granada, después de narrar toda la historia de la pasión y de la crucifixión entre los dos ladrones, expone la siguiente meditación:

Despierta, pues, ahora, ánima mía, y comienza a pensar el misterio desta santa cruz, por cuyo fruto se reparó el daño de aquel venenoso fruto del árbol vedado, como lo significó el esposo a la esposa en los Cantares cuando dijo: «Debajo de un árbol te resucité, esposa, porque debajo de otro árbol fue corrompida tu madre cuando fue engañada por la antigua serpiente». Mira, pues, cómo, llegado ya el Salvador a este lugar, aquellos perversos enemigos, porque fuese más vergonzosa su muerte, lo desnudan de todas sus vestiduras, hasta la túnica interior, que era toda tejida de alto a bajo sin costura ninguna (Huerga, ed., 1994: 88).

Fray Luis de Granada, en Introducción del Símbolo de la Fe, subraya la trascendencia simbólica del «árbol de la cruz», donde Cristo fue sacrificado.

Por otro lado, en algunos textos antiguos (no sólo en el Nuevo Testamento, también en los Evangelios Apócrifos), se ha visto a Jesús como una especie de mago, como se apunta muy certeramente en un trabajo de Amparo Pedregal (1991:324).

En la pieza de Corredoira descubrimos igualmente la influencia de otras obras religiosas, como La tristeza de Cristo (De tristitia Christi), de Santo Tomás Moro ${ }^{11}$ y lecturas laicas racionalistas, como el libro de Alfred Loisy, Los misterios paganos y el misterio cristiano, cuya tesis fundamental es la siguiente: «... las raíces principales del cristianismo se hundían no sólo en el judaísmo sino también en las antiguas religiones paganas, a través de los cultos de misterios» (Loisy, 1990:. 9). Es decir, Cristo vendría a representar en la nueva religión la misma función que Osiris en Egipto, Mitra en Persia, Dionisos en Grecia, etc., con los que a veces se le ha identificado. Todo ello relacionado con los mitos de la muerte y resurrección del Dios y mitos agrarios, en el sentido de Mircea Eliade en Traité d'Histoire des Religions. En esta concepción de Cristo como un mito universal, Corredoira se apoya también en el libro de Raimundo Panikkar, El Cristo desconocido del Hinduismo.

En 2008, el arqueólogo francés Franck Goddio descubrió entre las ruinas de Alejandría una vasija de cerámica con la inscripción en griego Dia Chrstou o goistais («Por Chrestos, el mago»). La inscripción habría sido realizada antes del año 50 d. C., y sería la primera referencia al Mesías que se conoce, pues hasta esa fecha el honor lo ostentaba una carta de San Pablo del año 51, donde habla de su maestro. Un poco más tarde, hacia el 93 d. C., contamos con el problemático Testimonium Flavianum incluido en las Antigüedades de los judíos de Flavio Josefo (XVIII, 3, 3). Corredoira lo considera

${ }^{11}$ La escribió en 1535 mientras aguardaba en la Torre de Londres su decapitación; o lo que es lo mismo: es su última obra, y quedó inconclusa. Una de las versiones españolas está publicada en Ciudadela Libros (Madrid, 2011). Al final del texto aparece este colofón en latín, donde se explica cómo no pudo terminar su obra porque fue privado por mandato de Cromwell de los pergaminos y del carboncillo que estaba usando: THOMAS MORVS IN HOC OPERE VLTERIUS PROGRESSUS NON EST, HACTENVS ENIM CVM ESSET PERVENTVM, OMNI NEGATO SCRIBENDI instrumento, multo arctius quam antra in carcere detentus: non ita multo post prope turrim londinensem loco consueto securi percussus est, secundo Nonas Iulii, Anno Domini supra millesimum quingentesimo tricesimo quinto, Regis vero Henrici octaui vicesimo septimo. 
problemático, porque un judío fariseo ortodoxo como Josefo habla en términos bastante favorables de Cristo, lo que ha dado lugar a sospechar que se trata, en algunos pasajes, de una interpolación de un escriba cristiano. Josefo se refiere a la Pasión de Cristo y a la expansión del cristianismo en estos términos:

Por aquel tiempo existió un hombre sabio, llamado Jesús, si es lícito llamarlo hombre, porque realizó grandes milagros y fue maestro de aquellos hombres que aceptaron con placer la verdad. Atrajo a muchos judíos y muchos gentiles. Era el Cristo. Delatado por los principales de los judíos, Pilatos lo condenó a la crucifixión. Aquellos que antes lo habían amado no dejaron de hacerlo, porque se les apareció al tercer día resucitado; los profetas habían anunciado este y mil otros hechos maravillosos acerca de él. Desde entonces hasta la actualidad existe la agrupación de los cristianos (Josefo [c.37- 100 d. C] 2013: 676).

Esa agrupación era vista como una más de las docenas de sectas que pululaban por Palestina en aquellos tiempos, y no de las mejores, según testimonio de Celso en su Discurso verdadero contra los cristianos: «Hay una raza nueva de hombres, nacidos ayer, sin patria ni tradiciones, unidos contra todas las instituciones religiosas y civiles, perseguidos por la justicia, universalmente marcados de infamia, pero que se glorían de la execración común» (Bodelón, ed. 1988:19). Es decir, son vistos como un grupo marginal y disidente porque no siguen los dictados del Imperio romano, no quieren hacer el servicio militar, son los primeros insumisos, etc.

En la recreación de la Pasión que lleva a cabo José Manuel Corredoira ocupan también un lugar destacado la obra De inventione, de Cicerón, los Salmos, las Epístolas de San Jerónimo, las Etimologías de San Isidoro, los sermones de San Agustín, las Meditationes de humana conditione, del pseudo Bernardo y la Plaza universal de todas ciencias y artes, de Cristóbal Suárez de Figueroa, de la que se aprovechan, como veremos, sus indagaciones neurológicas.

Entre los autores más cercanos en el tiempo a nosotros constituyen referentes fundamentales Ernest Renan, Arnold J. Toynbee, Giovanni Papini, etc. Toynbee en su Diálogo entre dos generaciones lleva a cabo un interesante parlamento con su hijo, en el que afirma que Cristo no era judío sino galileo, es decir, su trasfondo religioso era mucho más arcaico. En algunas escenas de la obra de Corredoira resuenan los comentarios que Ernest Renan en su Vie de Jésus expone en los capítulos XXV y XXVI: «Jésus savoura ces horreurs dans toute leur atrocité. Les deux voleurs étaient crucifiés à ses cotes (...) Il était environ trois heures de l'après-midi, selon nôtre manière de compter, quand Jèsus expira» (Renan, 1992: 225-229). En cuanto a Giovanni Papini, merecen citarse sus obras Historia de Cristo, La escala de Jacob, Los operarios de la viña y Los testigos de la Pasión. Este último libro de Papini, publicado en 1937, se inspira, según Corredoira, en Figuras de la Pasión del Señor, de Gabriel Miró (Miró, 1916-1917).

Corredoira también ha leído, aunque no influyen en su versión de la Pasión, las novelas recientes de J. M. Coetzee, La infancia de Jesús (2013), la de Ricardo Menéndez Salmón, Niños en el tiempo (2014) y el ensayo Pasión del dios que quiso ser hombre (2014) de Rafael Argullol. Sí desempeña en su pieza una función importante ese juguete cómico de Alfred Jarry La pasión considerada como una carrera ciclista, que en 1903, el año del primer tour, presenta a Cristo, cuando sube al monte del Calvario, como a un corredor especialmente adepto a la mala suerte. 
Con este impresionante equipaje, realiza su especial viaje José Manuel Corredoira en su recreación de la Pasión de Cristo. Los protagonistas son Gestas y Genas, «el mal ladrón» y «el buen ladrón», llamado Dimas, y que Corredoira cambia por Genas.

En Figuras de la Pasión del Señor de Gabriel Miró, se nos presentan con gran patetismo, plasticidad y dramatismo las torturas a las que fueron sometidos Genas y Gestas:

Genas torciose en una queja caliente y convulsa. Un soldado le arrancaba el sayal, renovándole las llagas de la flagelación. Todo desnudo, semejó más débil, estrecho, de un argadizo roído.

Los mílites, desde sus escalas, elevaban con correas el leño, en cuyos remates se estremecían las manos clavadas de Gestas...le doblaron las piernas hasta que la planta del pie se adhirió al tronco de la cruz. Dos siervos izaron rápidamente el harapo de Genas. Quedó en una quietud de síncope. Las piltrafas de sus labios se prolongaban en una sonrisa, se arrugaban en un sollozo... (Suárez Granda, ed., 1984: 274- 275).

Es impresionante lo que puede leerse sobre la ceremonia del crurifragium, la rotura de huesos en todas las extremidades para acelerar la muerte de los reos, y de la cual dispensaron a Cristo por la sencilla razón de que murió relativamente pronto: a las dos o tres horas de ser clavado en la cruz; los ladrones no tuvieron tanta suerte. Los soldados romanos tomaban una bebida llamada «posca» que consistía en vinagre y agua (acetum cum aqua mixtum), para aplacar la sed frente a los rigores del clima palestino. Es la que le dio a beber el legionario a Cristo en la cruz con una esponja. Pero el dramaturgo se pregunta si no estaba haciendo con esto un acto de caridad. En la Representación a la Pasión de Juan del Encina, la testigo Verónica no lo considera precisamente un acto caritativo: «iMirad cómo le tratava/ aquella gente cruel!/ que a bever vinagre y hiel/ muy crudamente le dava/ quando estava/ puesto por valança y fiel/ que la redención pasava» (Pérez Priego, ed. 1996: 786-787).

Verónica también se refiere la atrocidad con la que Cristo fue crucificado entre dos ladrones. «Cruelmente/ en medio de dos ladrones/ pusieron al inocente».

José Manuel Corredoira expone una reflexión que le conviene perfectamente a su recreación de la Pasión: «Lícita justísima y acabadamente/ puede decirse/ que en todo tiempo/ jamás fue leída ni vista/ por ojo alguno/ una comedia semejante a esta/ en esplendor y sang-froid» (Corredoira, 2014: 65).

Los textos, intertextos y argumentos de autoridad son muy numerosos, y nos encontramos, así, junto al Marqués de San Aubin, Artemidoro y San Ambrosio, la exposición, con fórmula incluida, de la regla de L' Hôpital, que debe su nombre al matemático francés del siglo XVII Guillaume François Antoine, marqués de 1' Hôpital, quien la dio a conocer en su obra Analyse des infiniment petits pour l'intelligence des lignes courbes (1696), el primer texto sobre cálculo diferencial, aunque quien la demostró y desarrolló fue Johann Bernoulli.

Se evoca a Miguel Hernández en «tanta felicidad/ para morirse uno», y continúa su juego intertextual en «Arrabal fui por naranjas/ al blanco y dulce cisne de Vilamorta», donde, por una parte, introduce a su amigo y admirado Arrabal en el contexto de la com- 
posición popular «a la mar fui por naranjas, cosa que la mar no tiene» ${ }^{12}$, que se canta en su Asturias natal, y, por otra, se alude a la obra de doña Emilia Pardo Bazán, El cisne de Vilamorta.

Sigue la historia de Genas y Gestas, con menciones a María de Magdala, pero también a la Baronesa von Thyssen, al ministro de Cultura, al Presidente y a la Vicepresidenta del Gobierno, con recursos como las derivaciones «pijo aparijo», «chivos al chivitero», «Bajá del bajalato», «Femme ¿infamado?», artificios como el calambur «Odieux! O dieux», juegos de palabras como «salsa mola», «no me tuitee usted»y « ¿Tragas habas?».

El discurso de Corredoira mezcla lo grave con lo cómico, y, junto a los préstamos de otras lenguas se recurre al neologismo y al léxico de germanía: «Gastaste el salterio Genas/ a la très douce chose/ que Dieu fist croistre/ a los que pintan jabeques/ María de Cleofás Hermiteón de Sibaris/ famosos bardajes/ al dulce apremio/ que brota de los chucháis/ inflamando el ánimo/ a la herejía de Novaciano/ fundador de la casa/ de perfumes Katharoi» (77-78).

San Jerónimo menciona varios escritos de Novaciano, de los cuales sólo nos han llegado dos, el De Cibis Judaicis y el De Trinitate. El primero es una carta escrita en su retiro durante el tiempo de la persecución, que fue precedida por otras dos cartas sobre la circuncisión y el Sabbath, que se han perdido. Aborda, entre otras cuestiones, las diferentes clases de vicios de los hombres y el problema de la libertad. En el De Trinitate se refiere a la trascendencia y grandeza de Dios, que está sobre todo pensamiento y no puede ser descrito por nadie. Novaciano pasa a probar la Divinidad del Hijo a grandes rasgos, con argumentos del Antiguo y del Nuevo Testamento. Estas y otras cuestiones sobre el pensamiento de Novaciano y sobre la secta del novacianismo han merecido la atención de John Chapman (1911) y de otros autores.

Corredoira alude a que Cristo pudo haberse casado, y presenta en su comedia como argumento de autoridad el descubrimiento de un antiguo papiro por la historiadora estadounidense Karen L. King, que denominó el texto como El evangelio de la esposa de Jesús ${ }^{13}$.

Sigue el desarrollo dramático, con sentencias senequistas como post mortem nihil, y con citas de los Pensamientos de Pascal, del Éxodo y de los Proverbios bíblicos, de las Etimologías de San Isidoro y De inventione de Marco Tulio Cicerón.

Lo que valora especialmente José Manuel Corredoira en De inventione y en otras obras de Cicerón es su capacidad para realizar una sabia simbiosis del discurso retórico y del pensamiento filosófico y que se instituya el sistema ciceroniano y en concreto el estudio de la Retórica en un curso de las artes liberales, como ha señalado la crítica literaria y filosófica (González Bedoya, 1990, I: 81).

Corredoira se refiere a «la Tierra del Pipiripao», considerada como uno de los lugares utópicos en la historia de la literatura. El motivo del lugar utópico y extraordinario, como comenta el profesor Miguel Ángel Pérez Priego, también es propio de los relatos

12 «A la mar fui por naranjas, cosa que la mar no tiene; me dejaron mojadita las olas que van o vienen. Ay, mi dulce amor, ese mar que ves tan bello, ay, mi dulce amor, ese mar que ves tan bello es un traidor. La farola de mi pueblo está partida en dos cachos: una alumbra a los marinos y otra alumbra a los borrachos. Ay, mi dulce amor, ese mar que ves tan bello, ay, mi dulce amor, ese mar que ves tan bello es un traidor....»

${ }^{13}$ Karen Leigh King, «The Gospel of Jesus's Wife: A New Coptic Gospel Papyrus», Harvard Theological Review, 106: 1 january, 2013. 
folklóricos, y a su difusión en la Edad Media contribuye la famosa carta del Preste Juan de las Indias, en la que se describe en términos fabulosos el país por él gobernado. En este país, que se extiende desde la India al desierto de Babilonia, la tierra mana leche y miel en abundancia, por él corre el río Indo que brota en el paraíso y arrastra piedras preciosas de todas clases... (Pérez Priego, 1984: 217-39; 1987: 57).

Este lugar utópico aparece también en las colecciones de refranes: «En la tierra del Pipiripao, donde no se conoce el trabajo, todos mueren de hartazgo» (Martínez Kleiser, 1982: 393, b).

En una aleluya madrileña se insiste en el mismo asunto (Caro Baroja, 1993: 62), que se halla también representado en dos obras del gran pintor flamenco del siglo XVI Brueghel el Viejo (Bastelaer, 1908: 146).

Los lugares paradisíacos son descritos con profusión en los libros de caballerías y en alguna novela picaresca. Así, en el Estebanillo González, el Delfinado se compara a esta tierra afortunada: «Llamaba a aquella provincia la tierra de Pipiripao».

Corredoira, un amante de tierras afortunadas y un rabelaisiano consumado, recurre nuevamente a juegos plurilingües e inserta una larga letanía a partir de la palabra «puta», como hace Rabelais a partir de «couillon».

Las putas han tenido una destacada representación en la historia de la literatura y del teatro y no siempre con el respeto que merecen y que les profesa nuestro autor.

En el siglo XVIII Nicolás Fernández de Moratín escribe El Arte de las Putas, que ha llegado a ser considerado como la guía secreta del Madrid de la época. En él aparece un amplio catálogo de nombres y lugares muy conocidos de la noche madrileña del siglo XVIII, además de recomendaciones en el trato con las prostitutas y el precio que debía pagarse por sus servicios, muy al estilo de otras obras europeas anteriores al autor como La rettorica delle puttane o La tariffa della puttane di Venezia. Incluso se ha señalado que Los Caprichos de Goya estuvieron inspirados en esta obra de Nicolás Fernández de Moratín. El Arte de las Putas circuló de forma manuscrita hasta su primera edición a finales del siglo XIX, de la que solo se imprimieron cincuenta ejemplares.

A finales del siglo XIX, Eduardo López Bago, uno de los máximos representantes del naturalismo radical, escribió una serie de novelas como La prostituta, La Pálida, La Buscota y La Querida, en las que se condenaba la prostitución y se responsabilizaba de la misma a los diversos sectores de la sociedad, incluido el clero. Alejandro Sawa, otro de los «naturalistas de barricada», se refiere igualmente a esta práctica y señala en novelas como en Noche la responsabilidad de los sacerdotes favoreciendo una perversa educación sexual.

En Elucidario sentimental del mismo Corredoira, el enunciador, con un cierto distanciamiento brechtiano, anuncia que dará comienzo a sus «dicharachos/ volúbiles/ astringentes»y se dirige apelativamente a sus «compañeras/ de armas», llamándolas «¡Putas mías!».

En su recreación de la pasión, Corredoira comenta que «en Judea Samaria Abatea/ Iturea Decapolis y Galilea/ había docenas de lupanares/ llamados así/ a causa de las lupae o lobas/ que los regentaban/ pues lobas son llamadas/ las meretrices por su rapacidad/ como cuenta San Isidoro/ Etimologías XVIII 42» (Corredoira, 2014: 78). 
En efecto, en el libro XVIII de las Etimologías, «Acerca de la guerra y los juegos», y en concreto en el apartado «Pompa diaboli: circenses, scaenici, gladiatorii», Isidoro comenta que el teatro recibe también los nombres de prostíbulo y lupanar, debido a las prostitutas que lo frecuentan (Etym. XVIII 42). También algunas prostitutas protagonizaban los argumentos de la comedias (Etym. XVIII 46), encarnadas por actores que, «vestidos con ropas femeninas, imitaban los gestos de las mujeres impúdicas (...) Es de todo punto evidente el patrocinio de Líber y de Venus en las artes escénicas y en todo lo propio y privativo de la escena, como son los gestos y flexiones del cuerpo. En efecto, ofrendaban a Liber y a Venus la sensualidad, unos por el sexo, y otros, disolutos, por el fasto» (Etym. XVIII 48).

Las «putas» reciben en la obra de Corredoira las más diversas calificaciones, muchas de ellas inventadas por el propio autor y otras tomadas del habla coloquial e incluso de algún texto bíblico como el de Jeremías (3.3). En algunos casos se explica el significado del calificativo, como en «putas escolásticas/ id est tommaseas».

Corredoira recorre todo el alfabeto para no dejar a ninguna en el olvido. Nos encontramos así con: «Putas atarazadas/ putas ausonias,/ putas auxiliadoras de la media luna roja/ putas axafitas/ putas ayalonitas/ putas babilonas/ putas bacalarias...» para terminar con las «putas zampalimosnas y las putas zorreras».

En este discurso intertextual se cita a Sócrates y a Marco Tulio Cicerón y se vuelve al hilo del relato bíblico con la mención del Qohéleth, que es el nombre hebreo del Libro del Eclesiastés. El autor se llama a sí mismo Qohéleth (תֶֶֶ), que significa literalmente «el hombre de la asamblea» o «el representante de la asamblea», el vocero, un tribuno de la asamblea del pueblo (Ubieta 856). "Vanidad de vanidades, dijo Qohéleth: vanidad de vanidades; todo es vanidad» (Eclesiastés, 1,2) se exclama en los primeros versículos del libro. En la obra de Corredoira, como en la comedia del Siglo de Oro, se llama a Cristo Segundo Adán y se le recuerda a Gestas que no hay revés de la suerte ni mal que no pueda sufrirlo la naturaleza humana. Se alude al Misterio de la Trinidad, de nuevo a María Magdalena y a las palabras que Jesucristo le dirige a esta mujer después de la resurrección: «Noli me tangere», aunque el discurso del autor las convierte en «Noli me tangueles/ con tu lengua parlera» (Corredoira, 2014: 89). En Elucidario sentimental se menciona igualmente la Trinidad y se la presenta de esta forma: «Padre/ Hijo/ y la paloma de Picasso» (Corredoira, 2013: 68).

Un diálogo intertextual con el Valle-Inclán del salutem plurimam de Luces de bohemia lo constituye el mortis imago plurima de Corredoira, de la misma forma que el ars longa, vita brevis, del De brevitate vitae (I, 1) de Séneca, que es a la vez una sentencia abreviada de Hipócrates, recibe su respuesta en esta obra de Corredoira: «Quanto es vita longior/ tanto culpa numerosior/ y qué bien dicho está / por San Bernardo de Claraval! / Meditatio de humana conditione II 5» (Corredoira, 2014: 89-90). Nuestro dramaturgo atiende especialmente a los primeros autores que escribieron sobre detalles de la Pasión, como Anselmo de Canterbury o Anselmo de Aosta, en sus obras De incarnatione y Cur Deus Homo (1094-1098), en las que destaca la naturaleza humana de Cristo y San Bernardo de Claraval, que también profesa una profunda devoción a la humanidad de Cristo.

A la vez, la cancioncilla popular Tres morillas me enamoran en Jaén: Axa y Fátima y Marién, recogida en el Cancionero musical de Palacio, y que ya encontramos en una 
ensalada de Pedro de Orellana en el siglo XVI, y en una versión a lo divino, halla igualmente su réplica en la obra de nuestro autor.

El dramaturgo sigue desarrollando las escenas de la muerte de Cristo y de los dos ladrones, intercaladas con citas de Les exercices de dévotion, los Sermones ad Populum $(169,11)$ de San Agustín, los Salmos $(31,10)$, Ad Paulinum presbyterum de San Jerónimo y los Anales eclesiásticos del cardenal Cesar Baronio, "más preciosos que el oro y el topacio», según escribió San Francisco de Sales. Felipe Neri influyó notablemente en César Baronio, a quien tres papas quisieron nombrar obispo, y al que Clemente VIII elevó a Cardenal y le concedió el más alto tributo a su erudición, al designarlo bibliotecario del Vaticano. Sus Anales vienen siendo considerados por los historiadores de la iglesia como documentos valiosísimos y los investigadores los han calificado como piedra angular de la verdadera ciencia humanística y han reconocido en su autor las cualidades de un historiador modelo.

El discurso dramático de Corredoira vuelve a la acción principal, y con nuevos juegos lingüísticos, el autor recuerda que vendieron a Cristo por «treinta siclos de plata/ de Israel contrastes y sonantes (...) el precio de un esclavo/ según Éxodo, 21, 32«/ dicen que Judas se compró / con ellos un vasar de alfarería / a María Salomé / desaciertos de la carne / a las que rúan la calle» (Corredoira, 2014: 92).

Este «viaje entretenido», como también hemos definido el teatro de Corredoira, recurre ahora a la Relazione del primo viaggio intorno al mondo, de Antonio Pigaffeta, que fue uno de los 18 hombres que regresaron de los 265 de la expedición inicial de Magallanes, y que constituye la fuente fundamental sobre esta magna empresa de circunnavegación del globo. Este relato, conocido también como la Relación de Pigafetta, es uno de los primeros documentos sobre el viaje de Magallanes, y un testimonio de la propia vida de Pigafetta y de sus experiencias por los mares y por espacios lejanos y desconocidos. Como explica el profesor Pérez Priego, hablando de otro ilustre viajero, «el viaje también es testimonio. Testimonio, por ejemplo, del esplendor de civilizaciones pasadas en el tiempo o lejanas en el espacio» (Pérez Priego, 2011: 138).

La Comedia humana de Balzac y los Fundamentos de Derecho Faraónico son las más grandes tendencias de la época, según el autor, que, expone ahora sus consideraciones sobre las obras de arte, la hermosura de la naturaleza y las ciencias puras, siguiendo a Cristóbal Suárez de Figueroa en su Plaza universal de todas ciencias y artes, y reflexiones sobre diversos aspectos de la vida de Jesús, de Judas Sarifeo, Matías de Margaloth y Herodes el Grande.

Suárez de Figueroa, por su parte, tiene muy en cuenta a Tomaso Garzoni, autor de El teatro de los cerebros y El hospital de los locos incurables (L'ospidale de' pazzi incurabili), el segundo de los cuales es considerado como un trabajo pionero sobre todas las formas de la locura. En 1585 publicó La piazza universale di tutte le professioni del mondo, y Suárez de Figueroa realizó una versión brillante de la misma en la Plaza universal de todas ciencias y artes (1615), adaptando al tiempo y al lugar los materiales de Garzoni. La obra de Suárez de Figueroa constituye una valiosísima fuente de información sobre el estado de diversas disciplinas y manifestaciones artísticas en el momento inicial de la revolución científica. Nos proporciona igualmente la visión de una sociedad convulsa, dominada por conflictos internos y sociales: 
Es la crisis mental que reflejaron Tasso, Böhme o Montaigne, Cervantes, Alemán y Sánchez, Bacon, Shakespeare o Donne (...) Como el recorrido va desde los más poderosos hasta los mendigos, desde los artistas hasta los sepultureros, no pueden faltar desde luego tres oficios universitarios de entonces: los jurisconsultos, que sin ser consumados en su Facultad pasan a las de filosofía o matemáticas, y hablan «de los más sabios con asco y gestos»; los médicos, de codiciosos deseos, que obran tantas veces a ciegas; y los teólogos que «los hace despeñar la demasiada sutileza de sus ingenios» (Landmarke, 2006:248-249).

Pero además de esas críticas ya seculares, la Plaza universal recoge miles de datos técnicos, citas eruditas, cuestiones médicas, reflexiones históricas, etc.

Corredoira hace bien en reflejar las consideraciones de Suárez de Figueroa, porque su obra es también una «plaza universal» en donde cabe todo, un rico mercado de esencias de todo tipo, un segundo mundo dentro del oficial (Bajtin, 1995: 139), una plaza pública, en la que asistimos a las más diversas representaciones y en la que alcanza un destacado protagonismo el carnaval.

La acción dramática está llegando a su final y por ello resultan muy pertinentes la cita de Beowulf (v.2891) y las palabras que cierran la pieza: «Gloria a Dios por todo/ Doxa to theo panton eneken/ nuda crux nudus/Y exhaló el alma/ del Arabia feliz».

Aunque Corredoira escriba en una de las últimas secuencias: cotidie praemoriamur, su recreación de la pasión de Cristo se aleja del tono luctuoso de este tipo de representaciones para ofrecernos un festín, un banquete semejante al de la Coena Cypriani, en el sentido en el que fue reelaborada por Juan Hymmonides, con alusiones a la política contemporánea y a las múltiples interpretaciones de la vida, y con intenciones fundamentalmente lúdicas. En definitiva, esta recreación de la Pasión constituye un tratado filosófico integrado por diversos tratados, un océano de referencias y de textos, un diálogo intertextual de autores de todas las épocas y tendencias, y todo ello construido con una profunda densidad semántica y conceptual, con los más deslumbrantes recursos formales, con una rica gramática jocosa, y con una portentosa demostración de los grandiosos poderes del lenguaje.

\section{BIBLIOGRAFÍA}

Artaud, Antonin (i99o). El teatro y su doble. Barcelona: Edhasa.

Arrabal, Fernando. (2008). «Assoiffé d'éternité/Sediento de eternidad». José Manuel Corredoira. Bestiario de amor. Ciudad Real: Naque Editora, 6-7.

Austin, John Langshaw(I996). Cómo hacer cosas con palabras. Barcelona: Paidós.

Bajtin, Misail. (1995) La cultura popular en la Edad Media y en el Renacimiento. El contexto de Françoise Rabelais. Madrid: Alianza.

Bastelaer, René Van (I908). Les estampes de Peter Bruegel l'Ancien. G. Bruxelles:Van Oest et Cie.

Benveniste, Émile (I97I). Problemas de lingüística general. México, D.F.: Siglo XXI Editores. Bodelón, Serafín (I989).ed. Celso, Discurso verdadero contra los cristianos. Madrid: Alianza Editorial.

Bond, EdWARd (1989). Pasión. El angosto camino hacia el profundo norte y Misa negra. Madrid: Cuadernos El Público, $n^{\circ}$ 4, Madrid.

Brachetti, Ángela. (2007). La pasión de Cristo: Representaciones religiosas, Paraguay, Perú y Filipinas. Málaga: Servicio de Publicación de la Diputación de Málaga. 
Cantalapiedra, Francisco y Torres Monreal, Francisco (i996). El teatro de vanguardia de Fernando Arrabal. Kassel: Reichenberger.

Caro Baroja, Julio (I993). Jardín de flores raras. Barcelona: Seix Barral.

Chapman, John (I9I I). «Novatian and Novatianism», The Catholic Encyclopedia. Vol. 11. New York: Robert Appleton Company.

Corredoira Viñuela, José Manuel (2008). Bestiario de amor. Ciudad Real: Ñaque Editora,

- (2010). Retablo de ninfas. Libros del Innombrable: Zaragoza.

- (2012). Iluminaciones al público. Madrid: Ediciones Antígona.

- (2013). Elucidario sentimental. Zaragoza: Libros del Innombrable.

- (20I4). Diferencias sobre la muerte. Ciudad Real: Naque Editora.

Darío, Rubén (i9i5) Prosas Profanas y otros poemas. París: Imprenta de la Vda. de C. Bouret.

ECO, UMberto (I995). Interpretación y sobreinterpretación. Cambridge: Cambridge University Press, 1995.

Eliade, Mircea (1949). Traité d'Histoire des Religions. Paris: Payot.

FABRE, JeAn (2009). La orgía de la tolerancia y otras obras teatrales. Santiago de Chile: RIL Editores.

Font, IsABEL. «Un inquietante y temible servidor de la belleza», El País, 6 de noviembre de 2008.

Forner, JuAn PABlo (2000). Exequias de la lengua castellana, sátira menipea, edición crítica: José Jurado. Madrid: CSIC.

García, Rodrigo (20I I). Gólgota picnic. Madrid: Centro Dramático Nacional.

González Bedoya, Jesús (I990). Tratado histórico de la retórica filosófica, 2 vols. Madrid: Nájera.

Goytisolo, Juan (20I0). «Nota prologal». José Manuel Corredoira. Retablo de ninfas. Zaragoza: Libros del Innombrable.

Gutiérrez Carbajo, Francisco (200I). Teatro contemporáneo. Alfonso Vallejo. Madrid: Ediciones UNED.

- (2007). La poesía del flamenco. Córdoba: Almuzara,

- (2009). «El animal no humano en algunas obras teatrales actuales», en Anales de la Literatura Española Contemporánea, 34. 2 (2009), 67 / 453 - 90/ 476.

- (20 I I). «Modalidades del teatro breve según su forma discursiva». José Romera Castillo (ed.), con la colaboración de Francisco Gutiérrez Carbajo y Marina Sanfilippo. El teatro breve en los inicios del siglo XXI. Madrid: Visor Libros, 157-178.

- (20I2). «¿Qué erotismo?», Erotismo y teatro en la primera década del siglo XXI, ed. de José Romera Castillo, con la colaboración de Francisco Gutiérrez Carbajo y Raquel García Pascual. Madrid: Visor Libros, pp.65-84.

- (20I3A). «José Manuel Corredoira». Francisco Gutiérrez Carbajo (ed.). Teatro breve actual. Barcelona: Edhasa (Clásicos Castalia), 2013. 501-502.

- (2013B). «Un retablo en un torrente. Prólogo». José Manuel Corredoira. Elucidario sentimental. Zaragoza: Libros del Innombrable, 2013. 7-23

Hermenegildo, Alfredo (1972). Teatro selecto de Lucas Fernández. Madrid: Escelicer.

- (1975). Renacimiento, teatro y sociedad. Vida y obra de Lucas Fernández. Madrid: Cincel.

Huerga, Álvaro ( I994). Fray Luis de Granada, Obras completas, I, Libro de la oración y meditación, prólogo de Antonio Garrigues Díaz-Cañabate. Madrid: Fundación Universitaria Española.

Insúa, Mariela y Mata,Carlos (20I3) eds. Pedro Calderón de la Barca, La siembra del Señor (Los obreros del Señor). Pamplona/Kassel: Universidad de Navarra/ Reichenberger.

Josefo, Flavio [c.37- 100 d. C] (2013). Antigüedades de los judios. Barcelona: Clie.

Kantor, TAdeusz (2010). Teatro de la muerte y otros ensayos (1944-1986). Traducido del polaco por K. Olszewska Sonnenberg. Barcelona: Alba. 
Kristeva, Julia (i969). Semeiotike: recherches pour une sémanalyse. Paris: Seuil, 1969.

Landmarke, Esteban (2006). Reseña de Cristóbal Suárez de Figueroa, Plaza universal de todas las ciencias y artes, Valladolid: Junta de Castilla y León, en Revista de la Asociación Española de Neuropsiquiatría, vol. XXVII, núm. 100 (2007), pp. 520-521.

Lázaro Carreter, Fernando (I970). Teatro Medieval. Madrid: Castalia.

- (I 990). «Teatro. Pasión», Blanco y Negro, 13 de mayo de mayo de 1990.

Le Clèzio, Jean-Marie Gustave (2006). Mondo et autres histories. Paris: Éditions Gallimard.

Lehmann, Hans-Thies (20I3). Teatro posdramático. Murcia: CENDEAC.

Lihani, John (1973). El Lenguaje de Lucas Fernández. Bogotá: Instituto Caro y Cuervo.

LOISY, Alfred. (1990). Los misterios paganos y el misterio cristiano. Barcelona: Paidós.

López Mozo, Jerónimo (20I2). «Retablo de ninfas», Estreno, Vol. XXXVIII, No 1, primavera, pp.115-116.

MaleKPour, JAMShID. (2004). The Islamic Drama (Drama Islámica Ta'ziya.). London: Publisher Frank Cass.

Marías, Julián. (1967). «La filosofía actual y el ateísmo». En VV.AA. El problema del ateísmo. Salamanca: Ediciones Sígueme, pp. 91-123.

Martínez Bonati, Félix (I972). La estructura de la obra literaria. Barcelona: Seix Barral, 1972.

Martínez Kleiser, Luis (I982). Refranero general ideológico español. Madrid: Hernando.

Martínez Martínez, María José (2009). «Los crucificados dolorosos góticos y el Santo Cristo de Burgos de la Iglesia de San Gil», Codex aquilarensis: Cuadernos de investigación del Monasterio de Santa María la Real (2009), $\mathrm{n}^{\circ} 25$.

Massillon, Jean-Baptiste (i 859). Les Chefs-D'Ouvre oratoires de Massillon. Paris: Librairie de Firmin Didot Frères, 1859.

MegID, M. (2009). Muaquīf y jedel fĩ shaar al-Husseiníe (opiniones y críticas en los rituales de Hussein). Beirut Líbano: Editorial Dar-Alhadi.

Miras, Domingo (20I2). «Contemplarnos desde las extravagancias. Prólogo». José Manuel Corredoira. Iluminaciones al público. Madrid: Ediciones Antígona, pp. 9-17.

Miró, Gabriel ( I9i6-i9i 7). Figuras de la Pasión del Señor. Barcelona: Doménech Editor.

MuÑoz CÁlIz, BERTA (2005). El teatro crítico español durante el franquismo, visto por sus censores. Madrid: Fundación Universitaria Española.

Ogden, Charles Kay-Richards, Ivor Armstrong (i964). El significado del significado. Buenos Aires: Paidós.

PanikKar, Raimon. (1994). El Cristo desconocido del hinduismo. Madrid: Grupo Libro 88.

Pavis, Patrice (1985). Voix et images de la scène. Pour une sémiologie de la réception. Lille: Presses Universitaires.

Pedregal, Amparo (I99i). «Jesús de Nazaret y la magia», El Basilisco, Segunda Época, no 7 , 1991, págs. 3-24.

Pérez Priego, Miguel Ángel. (1984). «Estudio literario de los libros de viajes medievales», en Epos, I, pp. 217-39.

- (1987). Ed. Teatro renacentista. Barcelona. Plaza \& Janés.

- (I994). Ed. Juan del Encina, Obra completa. Madrid: Biblioteca Castro.

- (2003). El teatro en el Renacimiento. Madrid: Ediciones del Laberinto.

- (2009). Ed. Teatro medieval. Madrid: Cátedra.

- (20I I). «Encuentro del viajero Pero Tafur con el humanismo florentino del primer cuatrocientos», Revista de Literatura, 2011, enero-junio, vol. LXXIII, nº 145, págs. 131-142.

Renan, Ernest (1992). Vie de Jésus. Édition intégrale. Paris: Arlea.

Ruano de la Haza, José María, ed. (2005). Pedro Calderón de la Barca, Las órdenes militares. Pamplona/ Kassel: Universidad de Navarra/ Reichenberger. 
Salinas, Pedro (I947). Jorge Manrique o tradición y originalidad, Buenos Aires: Editorial Sudamericana.

SAN IsidORO DE SEvilla (2004). Etimologías, texto latino, versión española y notas por José Oroz Reta y Manuel Antonio Marcos Casquero; introducción general por Manuel C. Díaz y Díaz, edición bilingüe, Madrid: Biblioteca de Autores Cristianos.

SÁnChez del BARrio, ANTONio (I987). «Algunas noticias sobre el tiempo de la Pasión Tradicional: El caso concreto de Medina del Campo», en Revista de Folcklore, nº 83, 1987.

Senabre, Ricardo (20I4). «Prólogo». José Manuel Corredoira. Diferencias sobre la muerte. Ciudad Real: Ñaque Editora, pp. 9-17.

Siciliano, Italo (1934). Francois Villon et les Themes Poetiques du Moyen-Age. Paris: Armand Colin.

Spang, Kurt (199i). Teoría del drama. Pamplona: EUNSA, 1991.

Suárez Granda, Juan Luis (I984). Miró, Gabriel (1916-1917). Figuras de la Pasión del Señor. Madrid: Plaza y Janés.

Surtz, Ronald (1983). Ed. Teatro medieval castellano. Madrid: Taurus.

Todorov, TVetan (I988). «El origen de los géneros», en Miguel Ángel Garrido Gallardo (comp.) Teoría de los géneros literarios, 31-48. Madrid: Arco/Libros.

Torroja Menéndez, Carmen - Rivas Palá, María (i977). Teatro en Toledo en el siglo XV: «Auto de la Pasión» de Alonso del Campo. Madrid: Real Academia Española.

Toynbee, Arnold J. y Philip (1966). Dialogo entre dos generaciones. Buenos Aires: Emecé Editores.

Ubieta, José Ángel (1967). «Eclesiastés», Biblia de Jerusalén. Bilbao: Desclée de Brouwer.

Wellek, René / Warren, Austin (I953). Teoría literaria. Madrid: Gredos.

Zambrano, María (I97I). "Filosofía y poesía». Obras reunidas. Madrid: Aguilar. 